\title{
¿Varones construyendo espacios de Igualdad? Desafíos en contexto de confinamiento (COVID-19)
}

\author{
Men building spaces with Equality? Challenges in a context of \\ confinement (COVID-19)
}

Dra. María Gabriela Córdoba*

Lic. Darío Ibarra Casals ${ }^{\star *}$

\begin{abstract}
Resumen
El aislamiento social preventivo en Argentina y Uruguay abre el análisis acerca de las masculinidades en el contexto de confinamiento por el COVID-19. ¿Cuál es la vivencia de los varones durante este encierro y aislamiento en el espacio doméstico, tradicionalmente femenino? Se trata de determinar los problemas regionales en las relaciones de género a partir de cuyo análisis se lograría la construcción de nuevos vínculos sociales igualitarios. La polarización social de América Latina hoy aún se centra en una lógica heteronormativa de las relaciones de género, que vindica el poder masculino hegemónico en el ámbito público y relega a las mujeres al ámbito familiar. El confinamiento actual impacta con diversos matices en las relaciones familiares, y así salen a relucir los diferentes conflictos acallados, y el mayor de todos: la violencia masculina. El desafío es que los varones puedan generar cambios positivos para acabar con el orden androcéntrico imperante.
\end{abstract}

\footnotetext{
* Doctora en Humanidades (área Psicología) titulada por la facultad de Filosofía y Letras de la Universidad Nacional de Tucumán, especialista en Psicoanálisis y Género (APBA-UK) y Psicóloga (UNT). Co-directora de la carrera de posgrado "Especialización en estudios de Mujeres y de Géneros", Facultad de Filosofía y Letras, UNT. Docente de grado (Asignatura Sociología) y posgrado e investigadora con experticia en ciencias sociales, psicología, sociología, metodología de la investigación y estudios de género. Co-coordinadora General de SOMOS*, Centro de Investigaciones en Géneros, Masculinidades y Diversidad del NOA, y Miembro de la Asociación Argentina de Sexología y Educación Sexual (AASES).

** Candidato a Doctor en Psicología (UCES - Argentina). Diplomado en Antropología Social y Política (FLACSO). Especialista en Educación Sexual, en Terapia Sexual (FLASSES Argentina/Colombia) y en Psicoterapia Psicoanalítica (AGORA - Uruguay). Egresado del Programa de Actualización de Psicoanálisis y Género (APBA - Argentina). Licenciado en Psicología (UdelaR - Uruguay). Director del Centro de Estudios sobre Masculinidades y Género OSC. Coordinador del Área Violencia Masculina del Centro de Estudios sobre Masculinidades y Género. Facilitador de grupos de Reeducación para Varones desde Modelo CECEVIM. Facilitador de Grupos en Masculinidades (Modelo WEM). Punto Focal MenEngage y MenCare - Uruguay.
} 
Palabras Claves: masculinidades, género, COVID-19, confinamiento, ámbito semiprivado.

\begin{abstract}
Preventive social distancing in Argentina and Uruguay opens the analysis of masculinities in the context of confinement due COVID-19 pandemic. What is the experience of men during this confinement and isolation within household environment, traditionally feminine? The aim is to determine the regional problems in gender relations from the analysis of which the construction of new egalitarian social ties would be achieved. The social polarization of Latin America today still centers on a heteronormative conception of gender relations that vindicates hegemonic male power in the public sphere and relegates women to the family sphere. The current confinement affects with different nuances in family relationships, and thus the different silenced conflicts come to light, and the greatest of all: male violence. The challenge is that the male can generate positive changes to end the prevailing androcentric order.
\end{abstract}

Keywords: masculinities, gender, COVID-19, lockdown, environment semi-privated.

Fecha de recepción: Mayo 2020

Fecha de aprobación: Junio 2020

\title{
Introducción
}

En este ensayo se pretende dar apertura al análisis y debate acerca de las masculinidades en el contexto de confinamiento (COVID-19) en Argentina y Uruguay, a partir de las medidas dispuestas de aislamiento social preventivo para toda la población, con carácter obligatorio en Argentina, y recomendado en Uruguay. El punto de partida lo constituye una serie de interrogantes acerca de la vivencia de los varones durante este periodo de encierro y aislamiento, que se realiza en el espacio doméstico, históricamente internalizado como femenino por el Patriarcado, y, en consecuencia, es decodificado como un espacio que podría poner en peligro el sentimiento de virilidad. Ser hombre es, ante todo, no ser bebé, mujer, ni homosexual (Badinter, 1993), por lo que la masculinidad opera a partir de procesos de diferenciación, exclusión y negación, previstos para que la construcción del varón se "descontamine" de esas posiciones sociales desvalorizadas y de los espacios propios de lo femenino.

La masculinidad se ha desplegado hasta el momento en el espacio público -el Ágora-, donde los varones se han desarrollado profesionalmente y han competido entre ellos por el crecimiento profesional y económico; mientras que la esfera doméstica ha sido un territorio asignado a las mujeres, un espacio en el que han desarrollado la empatía, el sostén y el cuidado hacia hijos, hijas y parejas, tanto de manera logística como emocional. Esto da lugar a que en la convivencia cotidiana en familia se generen situaciones de tensión y fricción, así como dificultades en el ejercicio de la corresponsabilidad en las prácticas de cuidado y en la domesticidad, que, en la gran mayoría de los casos, siguen puestas en manos femeninas. 
Asimismo, la situación actual de aislamiento con el tránsito por el ámbito público limitado da lugar a dos posibilidades: que el varón carezca de la posibilidad de trasladarse a él, por cierre de su espacio laboral, o que éste sea confinado al ámbito de lo privado (el hogar). Nos interesa pesquisar los escenarios de tramitación de ambas posibilidades por parte de los varones, así como su capacidad de gestión de las emociones: miedo, incertidumbre, frustración y rabia, por mencionar algunas, en este espacio, ahora semiprivado, del hogar.

Y si bien la presente situación de confinamiento comenzó en marzo de 2020, nos interrogamos acerca de cuáles sean los posibles resultados de esta crisis, respecto al vínculo de los varones consigo mismos y con las personas de su entorno más cercano. Así, se abren dos posibles consecuencias: la oportunidad para que los varones puedan generar espacios igualitarios, donde prime la comunicación y la alteridad, convirtiéndose en referentes y agentes de cambio para hijos e hijas, o si, por el contrario, se profundicen las diferencias genéricas y los imperativos de la masculinidad hegemónica, transformando los hogares en espacios de competencia, servidumbre femenina y autoridad parental. Nos preguntamos si es posible que esta situación favorezca que algunos varones adopten una posición más dominante, donde aumenten su agresividad, convirtiéndola en violencia, para sentirse así más viriles, recuperando lo que Donna Haraway (1995) denomina plusvalía de género, reconociendo que la situación de confinamiento se convierte en un caldo de cultivo para la violencia machista, por lo que muchas mujeres, niños y niñas, se encontrarían más expuestos a la violencia doméstica.

El objetivo del presente ensayo es abrir el debate sobre los problemas regionales en las relaciones de género, en pos de que su análisis permita la construcción de nuevos vínculos sociales igualitarios y democráticos.

\section{Un mundo globalizado}

Las tres últimas décadas del siglo XX implicaron un profundo proceso de transformación social, en el cual las consecuencias de la modernidad se radicalizaron y universalizaron, por lo que Giddens (1995) lo denominó como modernidad tardía o mundialización de la modernidad. A diferencia de las sociedades tradicionales, esta sociedad de la mundialización se caracteriza por ciertas discontinuidades: el desanclaje espacio-temporal, -que intensifica las relaciones sociales en una modalidad de red global que no requiere de presencia-, la celeridad excepcional del ritmo de cambio y una transformación intrínseca de las instituciones, que, en su carácter intensivo, penetra en las esferas más íntimas del sujeto, generando un intenso efecto en la subjetividad. Este fenómeno global gesta en el mundo nuevas formas de estratificación social y cambios en las instituciones.

A nivel mundial, la expansión comercial y la amplia circulación de capital, productos y recursos se realiza en el contexto de un modelo neoliberal de desarrollo. Pero este énfasis en la productividad, la eficiencia y la recompensa financiera no ha sido inocuo, pues ha ido acompañado por una serie de cambios en los valores y en las actitudes sociales, caracterizados por acentuar el individualismo y la competencia, junto con una aparente tolerancia y aceptación de la desigualdad social e, incluso, de 
la codicia, pues el modelo se sustenta en la idea de que el beneficio y la ganancia son objetivos moralmente aceptables.

Y aunque es necesario destacar que la expansión del proceso de mundialización en términos económicos y políticos no involucra un proceso simétrico respecto a la expansión de una cultura mundial, sí está sostenido por la imposición de un discurso hegemónico y de una propuesta de modelo civilizatorio que se presenta como infalible, ubicando al mercado total como hilo conductor, fin en sí y utopía absoluta. Esto profundiza cada vez más la brecha que separa a los ricos de los pobres y está llevando al límite la lógica del beneficio por encima de cualquier proyecto ético y político de desarrollo humano.

Asimismo, la reestructuración globalizada se produce marcada por el género, afectando de manera diferente a hombres y a mujeres, debido tanto a la situación estructural de cada grupo, como a las relaciones de poder vigentes en la sociedad, asociadas con la posición ocupada en la división sexual moderna del trabajo. A partir de la simbolización sociocultural de la diferencia sexuada, se observan desigualdades estructurales en clave de género: un patriarcado de versión neoliberal y globalizada, que induce a pensar, sentir y funcionar en clave típicamente masculina y deja intacta la subordinación a los varones; y una feminización de la pobreza, implicando que los prejuicios y estereotipos de género asociados a las mujeres -además de la maternidad-, ejercen influencia sobre la lógica distributiva capitalista. Los basamentos ideológicos sobre los que se asienta el proceso globalizador neoliberal siguen siendo patriarcales, con su profunda carga legitimadora de las inequidades de género.

\section{Latinoamérica y sus particularidades}

El proceso de mundialización en América Latina se ha caracterizado por un fenómeno de amalgamado (Garretón, 2001) entre la sociedad industrial de tipo nacional (cuyos ejes eran la política, el trabajo, y la producción) y la sociedad globalizada, con grandes dificultades para sostener la actualización tecnológica y con un deterioro de los términos del comercio internacional, particularmente por la declinación general de los precios de sus productos y el empeoramiento de la balanza de pagos por préstamos y créditos gubernamentales y empresariales, así como por la repatriación de las inversiones extranjeras y la fuga de los capitales nacionales hacia el extranjero. El cambio de paradigma económico y la imposición del modelo neoliberal y de las políticas de ajuste estructural han tenido como efecto una desregulación del mercado laboral, con importantes repercusiones tanto en los sujetos -especialmente en el papel del varón como proveedor-, como en las relaciones entre los géneros.

En lo referente a la política latinoamericana, el siglo XXI trajo diversas tendencias entrecruzadas: por un lado, aquellas que muestran una ruptura con el modelo excluyente instalado en los '90 -con todas sus complejidades y matices- y manifiestan la intención de reparar el tejido social, recuperar el papel del Estado y favorecer la integración social de modo progresivo (Quiroga y Pagliarone, 2014); y, por otro lado, las que señalan la tentativa de reconstrucción de una gobernabilidad neoliberal, a través de la continuidad y profundización de esquemas de disciplinamiento económico, social y político que tienden a dejar de lado o a subordinar las metas sociales. 
Las desigualdades sociales que hoy muestran los países de la región dan cuenta de altos niveles de carencias, en medio de una riqueza potencial en producción de alimentos, recursos naturales y producto bruto interno. Esto va de la mano con un proceso de polarización social muy acentuado, con reconcentración de poder en ciertos grupos y un aumento de la desigualdad, con el consiguiente aumento de la pobreza (PNUD, 2016). Las políticas sociales desarrolladas en la región a partir del 2002, se han centrado fundamentalmente en un modelo ideal de familia y en una concepción heteronormativa de las relaciones de género, por lo que las actuaciones institucionales derivadas de estas políticas fomentaron un modelo de ciudadanía que vindicó el ejercicio del poder masculino en las relaciones, a partir de la separación público/privado, dejando a las mujeres como representantes de los intereses familiares, en especial los referidos al cuidado de infantes, de adultos mayores y de la salud de todo el grupo familiar. Y a pesar de la existencia en algunos países de políticas sociales que supuestamente incluyen un enfoque de género, no existe un abordaje que circunscriba a varones y a mujeres como sus destinatarios desde la perspectiva relacional del género, porque aún se apoya en una organización espacial moderna de la división sexual del trabajo.

\section{Patriarcado y división sexual del trabajo}

La estructura económica del capitalismo globalizado y neoliberal sostiene una "división entre tareas reproductivas pagas y no pagas; y entre el trabajo pago y altamente pagado, en los que prevalecen los varones, y las actividades de bajos ingresos, servicios y trabajos domésticos, atribuidas a las mujeres" (Fraser, 2003:23); partición sexual moderna del trabajo que se ha valido del sistema sexo/género, de la separación binaria público-privado y de la asignación de varones y mujeres a cada uno de ellos. Dando lugar a una organización esencial de la realidad social que se vive a nivel de la experiencia individual, conformando un entramado social donde las relaciones de género se estructuran valiéndose de recursos y de responsabilidades, que dan lugar a intercambios entre varones y mujeres no exentos de conflictos, en tanto combinan en su interior tres dimensiones, tal como plantea Connell (1987), que dan cuenta de:

1. relaciones de poder: hacen referencia a los modos de ejercer autoridad y de poner reglas dentro de un ámbito determinado, y se apoyan históricamente en modelos de dominación masculina y subordinación femenina;

2. relaciones de producción: dan cuenta de la división del trabajo y la distribución de los recursos en el ámbito social, tanto en su esfera pública como privada. Así, en el hogar, ámbito privado por excelencia, el trabajo incluye los cuidados domésticos y las responsabilidades familiares, mientras que en lo público tradicionalmente la producción laboral se ha dado mediante la asignación de tareas y responsabilidades jerarquizadas entre hombres y mujeres.

3. las relaciones de afecto y la sexualidad: incluyen el entramado de deseos, amores, sexualidad y erotismo, encuentros y desencuentros entre los géneros.

Las relaciones de poder, de producción y de afecto y sexualidad, se encuentran interpenetradas en la realidad e inscriptas en el marco del sistema social 
patriarcal, que instituye relaciones de poder, dando lugar a una naturalización de la subordinación de las mujeres y a una institucionalización del dominio masculino, lo que consolida con fuerza al patriarcado como una realidad y como una ideología (Lerner, 1990). En consecuencia, hombres y mujeres se sitúan en clases antagónicas, donde los primeros (hijos, hermanos, padres y maridos) explotan a las mujeres, para apropiarse de su trabajo doméstico, el cual es invisibilizado como trabajo (Delphy, 1981).

En el mundo social ha existido una jerarquización del mundo público por sobre el privado, con una división del trabajo y distribución de recursos en función del género. Esto ha tenido efectos sobre la subjetividad, en tanto ha dado lugar a identidades masculinas y femeninas con una modalidad excluyente, basadas en construcciones sociales complementarias de lo masculino y lo femenino que preexisten al sujeto, y que se constituyen en organizadores privilegiados de una subjetividad diferenciada, donde la socialización y los vínculos con otros van construyendo regulaciones que prescriben desempeños de género, proscriben comportamientos y asignan roles específicos para cada sexo. Así, las características psicológicas, económicas, sociales, culturales, jurídicas y políticas atribuidas a hombres y mujeres se adquieren y se construyen sobre los cuerpos sexuados machos o hembras, determinando una clasificación cultural que define tanto la división del trabajo, las prácticas rituales y el ejercicio del poder, como las características exclusivas y distintivas esperadas para hombres y mujeres en los aspectos morales, afectivos y psíquicos. En este sentido, las constituciones subjetivas, armadas sobre un andamiaje de construcciones sociales que constituyen posiciones y prácticas de género, se definen y transforman cuando contextos sociales, económicos, culturales y políticos mutan. Hoy esto se está produciendo de la mano de la pandemia del COVID 19, lo que requiere contextualizar su aparición y su replicación tanto global como regional.

\section{COVID-19: el contexto social de pandemia}

A fines del año 2019 se declara una alerta sanitaria global a partir de una epidemia en la ciudad de Wuhan (China), ocasionada por la diseminación de un agente patógeno llamado Coronavirus. El 11 de marzo del año 2020, la OMS la nomina como la Pandemia del COVID-19. En el mes de mayo de 2020, se contabilizan 212 países con contagios de Coronavirus, pertenecientes a los siete continentes del mundo.

Los efectos nocivos que tiene la pandemia, -por el fácil contagio y la rápida diseminación viral-, han impactado en los sistemas sanitarios de tal manera, que no se ha podido responder de manera eficaz y eficiente a todos los casos, lo que ha producido miles de muertes en los casos graves por Síndrome Respiratorio Agudo Grave (SARS). Este escenario condujo a los gobiernos de los países afectados a tomar medidas restrictivas de convivencia en la vida pública, confinando a la población a una vida en situación de cuarentena, distanciamiento social y aislamiento. Se entiende por cuarentena la separación de las personas que no tienen síntomas del virus de las que sí lo presentan, tanto para evitar el contagio, como el riesgo de ser expuestos al mismo. 
Como consecuencia de esta situación, los países latinoamericanos sufrieron fuertes impactos en diversas dimensiones de la vida privada y colectiva, sobre todo en temas vinculados con las relaciones de género, tanto por la situación de confinamiento obligatorio en los hogares, como por el nuevo escenario económico y político en la región. Así, en el Río de la Plata -Argentina y Uruguay-, han quedado expuestas las profundas desigualdades en cuanto a recursos materiales (vivienda, alimento y servicios básicos) y emocionales que tiene la población en general, lo que se observa claramente en los sectores de mayor vulnerabilidad social. En Argentina, el aislamiento social obligatorio se decretó el 20 de marzo, mientras que en Uruguay se solicitó a la población "quedarse en casa", aunque sin el carácter de obligatoriedad del país vecino. Por esta razón, el mundo privado -el hogar-, se ha convertido en un espacio de convivencia cotidiana obligatoria para toda la familia durante todo el día, y las instituciones laborales, que otrora eran propias de los espacios públicos, se han trasladado a la esfera privada, a partir del teletrabajo o trabajo remoto.

Las medidas de confinamiento, de distanciamiento social y el uso de barbijos (mascarillas) se enmarcan en la idea de combatir un virus real que pone sobre la mesa la amenaza de enfermar y también la posibilidad de morir. Todo este contexto tiene incidencia en los comportamientos de los sujetos, en sus respuestas, en sus prácticas y en sus relaciones, así como en su percepción de los procesos y en las estrategias que generan frente a la actual complejidad social. Por ello, enmarcado en este contexto particular, el análisis de aspectos subjetivos adquiere relevancia. La situación actual de pandemia por el COVID-19 no sólo genera en la población sentimientos de incertidumbre, miedo, frustración, tristeza y rabia, sino que produce un gran impacto en la vida de las personas, con matices diversos, acorde a la manera como cada sujeto puede manejar su capacidad de frustración frente al confinamiento y sus efectos. Hay quienes encuentran refugio e ilusión de seguridad y certeza en el cumplimiento de los protocolos, y están los que sienten que los mismos vulneran su libertad, pues no pueden disponer hacer las cosas a su modo. Se distinguen, entonces tramitaciones psíquicas de distinta índole: desde la total prescindencia de medidas de cuidado, hasta el pánico de quien se representa tan vulnerable que cualquier mínima modificación de su cuerpo lo hace sentirse contagiado, pasando por algunas personas que encuentran un gran bienestar al no tener que enfrentar la calle 0 al descubrir lo nuevo en actividades o en vínculos, sin olvidar otras que descubren que los lazos más cercanos estallan en la convivencia prolongada. En este último sentido, se observa que la cotidianeidad compartida de modo obligatorio en los hogares genera una frustración tal, que salen a relucir los conflictos de las relaciones de género, como, por ejemplo, la violencia masculina hacia las mujeres, niños, niñas y adolescentes. En pocas semanas, las tasas de denuncias por violencia doméstica y femicidios han aumentado exponencialmente, tanto en Argentina como en Uruguay, lo que preocupa sobremanera a quienes trabajamos en pos de fortalecer y mantener la salud mental y comunitaria.

\section{Los Varones en el marco del COVID-19}


A partir de los datos aportados por sesenta y nueve países sobre los casos diagnosticados y número de muertes reportadas por COVID-19, es posible observar que el género es un determinante impulsor de riesgo y de respuestas a la enfermedad, dando lugar a que se reporte una mayor proporción de varones afectados (Global Health 5050, 2020). Esto no quiere decir que los varones tengan un patrón biológico que aumente las probabilidades de infectarse con COVID-19 -al menos no se ha comprobado hasta la fecha-, sino que hay otros factores de riesgo incrementando la letalidad y la mortalidad de los varones, y el coronavirus simplemente multiplica esa probabilidad de morir. Los hombres combinan la temeridad con la omisión de cuidado, aumentando el riesgo: los varones tienen conductas temerarias al no mantener la distancia recomendada, al no utilizar tapabocas, al no cumplir con las medidas de higiene recomendadas, así como al no respetar la cuarentena y el confinamiento, pues ellos "siempre tienen que" salir a trabajar -por el rol de proveedor determinado culturalmente e internalizado en la subjetividad de los varones-, implicando una exposición mayor a contraer y a contagiar el COVID-19 a otras personas. Los varones fueron criados para circular por la vida sin temor, sin enfermarse y sin pedir ayuda, porque eso sería una muestra de debilidad. Los varones que transgreden el aislamiento, con una gran dosis de irresponsabilidad social, esconden una larga lista de debilidades: una crianza represora de las emociones, la provocación al peligro para reforzar la idea de "masculinidad", en definitiva, la fantasía del supermacho, que se ha constituido asfixiando la vulnerabilidad. El problema es que su falta de autocuidado expone también al otro $u$ otra a su mismo peligro, con una enorme dificultad de pensar en ello.

En este sentido, Figueroa (2020) sostiene que las condiciones que incrementan la probabilidad de morirse se vinculan con los procesos de aprendizaje de ser hombre, porque la masculinidad, lejos de ser una esencia, es una construcción cultural; el que nace con dotación genética $X Y$ debe aprender a ser hombre, ajustándose $e$ identificándose con valores, intereses y atributos que la normativa del sistema sexo/género adjudica a la masculinidad.

La subjetividad masculina, entonces, es resultado de un proceso en el cual, de modo singular, un sujeto metaboliza y recompone las representaciones genéricas y los mandatos hegemónicos de la virilidad, los cuales, con una enorme fuerza configuradora, van estructurando en el varón gestos, posturas, maneras de pensar y sentir asociadas a lo que se espera de él en tanto hombre, que luego se externalizarán como prácticas, poniéndose en juego en los vínculos con otras personas. Cuando los sujetos internalizan y asumen como propias las prescripciones sociales de la masculinización hegemónica, constituyen en su sí mismo, rasgos subjetivos que suponen rechazo de la demostración afectiva y dificultades para hablar sobre los sentimientos, necesidad de legitimación viril por parte de los pares y un posicionamiento jerárquico rígido, con remarcada superioridad sobre las mujeres. Como consideran que deben "limpiar" de sí todo aquello que evoque o se asocie a la pasividad, a la dependencia y a la femineidad, los varones enmascaran las necesidades de proximidad e intimidad con comportamientos temerarios, homofóbicos y misóginos, con un posicionamiento distante y asimétrico, que da lugar a prácticas de dominio. Se observa en los varones cierta "ortopedia" corporal y comportamental, en tanto se le exige al cuerpo rigidez y contención en sus movimientos y expresiones para 
ser realmente masculino, con la obligación de demostrar hombría, fuerza, actividad compulsiva, tenacidad, competencia, temeridad y dominio. El enorme costo es la distancia y la desconexión afectiva a la que se someten con el fin de ser una "máquina que rinda en el trabajo", llevándolos también a tener dificultades para percibir su propio cansancio, pues se los socializa con la idea de que una actitud cuidadosa y preventiva no es masculina.

Figueroa (2020) propone problematizar el hecho de cómo se aprendió a ser hombre, y qué elementos socioculturales colaboran con la formación de los varones en tanto tales. $Y$ apela a la idea de llevar adelante acciones efectivas que des-alienen al varón, que puedan deconstruir el modo de ser hombre, con el propósito de estimular el "cuidado de Sí", un concepto de Foucault (1987), entendido como un conjunto de prácticas mediante las cuales un individuo establece cierta relación consigo mismo, constituyéndose en esta relación en sujeto de sus propias acciones. Destaca Foucault que el cuidado de sí abarca una actitud respecto a sí mismo, respecto a los otros y respecto al mundo. La actitud respecto de sí mismo implica prestar atención a lo interiorizado en el pensamiento, una práctica de la subjetividad para sí mismo: una revisión de los modos con los que se ha intentado orientar la conducta para pulir sus formas, sus procedimientos, para hacerse cargo, para transformarse y transfigurarse. El cuidado de sí presupone el reconocimiento de la existencia del otro, y la toma de conciencia de que la posibilidad de relación intersubjetiva es una condición de la existencia. Cuidar de los otros supone reconocer al otro como alguien que existe y que tiene valor, y para ello es necesario que la persona se preocupe por poner atención a sí misma y a su contexto durante toda su vida, buscando siempre transformarse y conseguir una mejor convivencia con sus pares, teniendo claridad frente a la interdependencia de la vida humana con su mundo humano, social y natural. Esta noción de cuidado de sí supone, entonces, cuestionar muchos de los mandatos de la masculinidad hegemónica, tarea primera para que luego los hombres cambien la relación que establecen con su propio cuerpo, con los otros y con su entorno, en pos de la salud y del bienestar, cuidando en colectivo, acompañando, pero también dejándose cuidar.

\section{Lo público y lo privado en el contexto de la Pandemia}

La tradicional separación de esferas sociales entre lo público y lo privado ha sido erosionada por la globalización de las tecnologías comunicacionales, la organización económica y financiera de las empresas, y la reestructuración transnacionalizada de las "comunidades" de ciudadanos y consumidores (García Canclini, 1996). Esto ha dado lugar a estudios interesados en redefinir la esfera pública, entendiéndola como "un mosaico complejo de esferas públicas de diferentes tamaños, sobrepuestas e interconectadas" (Keane, 1995:8), entre las que se distinguen las esferas micropúblicas, los espacios locales en los que decenas, centenares o miles de participantes interactúan; las esferas mesopúblicas, que hacen referencia a las interacciones al nivel del Estado-nación, las cuales involucran a millones de personas y están mediadas por las tecnologías de la información y la comunicación; y las esferas macropúblicas, que ponen en relación a centenares de millones y aun billones de personas en los procesos económico-productivos 
globalizados. Estas tres esferas de lo público interactúan entre sí y con los ámbitos privados, dando lugar a una porosidad nunca antes vista.

Pero, ante la situación de confinamiento por la pandemia provocada por el COVID-19, resulta trascendental revisar las transformaciones actuales de lo público/privado en el contexto específico del hogar. La reorganización del espacio, generada por el confinamiento, ha dado lugar a nuevas modalidades de articulación entre lo público y lo privado, lo que nos lleva a la necesidad de construir nociones intermedias, por ejemplo, la de 'semiprivado', para nombrar las oscilaciones entre los extremos de este par. El proceso de confinamiento perfila el modelo de una "vida semiprivada", donde lo subjetivo y lo relacional del hogar sufre la irrupción de la esfera pública a partir de la puesta en escena del trabajo otrora extralaboral al interior del hogar, con la irrupción del teletrabajo, en una escala que anteriormente hubiese resultado impensable, y que no ha permitido una adaptación ni espacial ni emocional, dando lugar a estrés y desbordes de ansiedad y de angustia, tanto de los varones como de las mujeres. El teletrabajo en el mundo hogareño dificulta poner límites a los tiempos de trabajo y organizar el espacio, alterando de este modo la dimensión temporo-espacial, que "se transformó en circular por el encierro, que nos arrojó a una privacidad permanente" (Franco, 2020:8) y despoja de la posibilidad de trabajar en las condiciones habituales, y de contar con momentos a solas, todos compartiendo todo el tiempo. No hay que dejar de mencionar que, en el caso de Uruguay, en el mes de marzo, abril y mayo de 2020, ya hubo 180.000 personas en seguro de paro, implicando que hay miles de varones en sus casas, sin trabajar; situación similar a la que se vive en Argentina, donde la crisis ha impactado principalmente en trabajadores informales y monotributistas, que enfrentan los mayores riesgos de sufrir deterioro en sus condiciones de vida.

A partir de ello, surgen elementos de tensión y de fricción que impiden el contacto intersubjetivo familiar en un marco de tolerancia, pues se produce un interjuego de acercamiento $y$ de distanciamiento afectivo que genera enormes malestares. La familia se encuentra atravesada por prácticas de poder y autoridad, donde las tareas que deben ser realizadas en el espacio de la casa relativas a la crianza de hijos e hijas, a la limpieza, a la preparación de comidas, etc., se encuentran diferencialmente asignadas, en clave generacional y de género. Como el ámbito del hogar es considerado un espacio femenino, los varones tienden a participar poco o muy poco de las actividades domésticas cotidianas, pareciera que por temor de 'contaminarse' y poner en peligro su masculinidad. Como siguen sosteniendo que para ser masculinos deben acatar las exigencias del modelo hegemónico viril, tienen expectativas de servicio por parte de las mujeres, es decir que, a partir de su auto percepción aprendida de superioridad, los hombres esperan que las mujeres los sirvan y atiendan en la mesa y se ocupen de su cuidado, en una clara maternalización del vínculo de pareja. La mujer suma más y más tareas, mientras ellos evitan toda actividad catalogada culturalmente como femenina, complejizando más el panorama frente a las incertidumbres difíciles de tramitar que traen aparejadas estos tiempos de confinamiento.

Las jerarquías de género dentro de las familias se reflejan también en una determinada distribución de los recursos y de los espacios físicos. Históricamente, los espacios de dominio masculino han sido el living y el comedor, mientras que la cocina 
era el espacio femenino por excelencia -uso espacial instrumental, destinado a que la mujer preste un servicio-. Y aunque con el correr del tiempo esta división fue perdiendo peso, con el advenimiento del confinamiento lo espacial ha cobrado una nueva importancia, y ha dado lugar a una nueva construcción de fronteras en el interior del hogar para que se puedan desarrollar conjuntamente las tareas de la vida cotidiana: educación de los hijos, trabajo de los padres, y prácticas domésticas (dormir, cocinar, comer, limpiar). En las familias se producen enredadas articulaciones de lo privado doméstico con la privatización de la vida pública, dando lugar a ambigüedades y tensiones que vuelven inadecuadas la clásica oposición de este par. $Y$ es en el seno de la vida hogareña donde la problemática del cuidado se encuentra hoy más que nunca en el centro de la nueva cuestión social. La familia, entonces, opera en este contexto de pandemia como lugar de conflicto y de disputa de intereses.

En cuanto a los modos de ejercer autoridad, de definir y administrar reglas -0 de subordinarse a ellas- dentro del ámbito familiar, históricamente se trató de un dominio masculino, donde la autoridad del varón sobre la esposa y los hijos ha sido uno de los pilares en los que se asentó la definición de masculinidad hegemónica. La legitimidad de la autoridad del padre parecía confirmada tanto por su participación en el mundo de lo público como por la adhesión a un orden simbólico patriarcal que consolidaba la imagen de los varones como seres más fuertes, más racionales y autónomos que las mujeres. Así, los hombres adultos asumían un rol de "gerentes administrativos autoritarios", dado que eran quienes establecían las reglas en la casa, frecuentemente haciéndolo de modo vertical, con un principio de autoridad muy cercano al autoritarismo, que se ponía en práctica tanto en sus relaciones con la esposa como con los hijos.

Actualmente, las relaciones de poder entre los géneros construidas por el modelo patriarcal se encuentran parcialmente deslegitimadas, dando lugar a ciertas fisuras en el modelo tradicional, que convive con la emergencia de algunos modelos paralelos. Hoy pareciera haber un cambio en la modalidad de la puesta de normas en el hogar, pero no un cese de las jerarquías, pues, al menos en su mundo representacional imaginario, los varones siguen sintiéndose 'gerentes'. La nueva dinámica de relaciones de poder familiar vincula a hijos e hijas en algunos procesos de toma de decisiones; sin embargo, esta circulación de poder de modo horizontal no se valora de modo positivo en todos los casos.

Algunos varones celebran la ampliación de sus posibilidades de expresar emociones y conectarse mayormente con sus hijos, hijas y parejas, pero difícilmente puedan renunciar a algunos de los privilegios que les brinda el tránsito por el mundo público, implicando que buscan trasladar dichos privilegios al hogar, el nuevo espacio semiprivado. La flexibilización de patrones por parte de los varones convive aún con rígidos mandatos estructurados, en donde parecerían desear que las fronteras no cedan tan fácilmente. Esto aparece tanto en la responsabilidad doméstica como en las prácticas de crianza -depositadas en manos de las mujeres-, como en exigir un grado mayor de autonomía relativamente a su favor, lo que muestra cómo el modelo patriarcal ha comenzado a tomar formas sutiles que lo perpetúen, reconfigurado, aunque presenta ciertas fisuras que traen aparejadas la posibilidad de transformaciones. 
Se plantea, entonces, si la flexibilización de los modelos de autoridad, evolucionará, o no, hacia la democratización de las familias, ¿Podemos suponer que en el futuro las reglas serán cada vez más acordadas y las relaciones entre generaciones y géneros serán más equitativas en el seno del hogar? Consideramos que, aunque en algunos hogares esto puede convertirse en una realidad, coexistirán con modelos de familias donde la verticalidad, e incluso la violencia, continuará constituyéndose como la modalidad imperante de imposición de las reglas domésticas, pues por debajo subyace un temor, presente en algunos varones, de perder poder frente al avance femenino, desencadenando en ellos un sentimiento de 'impotencia vital' (Córdoba, 2020) que ha dado lugar a una vuelta a comportamientos más tradicionalistas, como manera de intentar evitar el vacío definicional que implicaría alejarse de la posición de masculinidad conocida. La posibilidad de construir cambios más democráticos al interior de la familia da lugar a discursos políticamente correctos que ocultan la permanencia de estructuras tradicionales, más invisibilizadas, con prácticas parcialmente deconstruidas: los varones dicen participar mucho más en las tareas domésticas, pero lo hacen en forma asistemática y a modo de colaboración, sin asumir responsabilidad por la tarea. Ello coexiste con el caso de varones que se atrincheran, con mucho ahínco, en un tradicionalismo vetusto frente a los cambios en la organización familiar, y que continúan con un desempeño de rol con características conservadoras, al reproducir de modo acrítico los mandatos del ser hombre acuñados dentro de la hegemonía viril. Esto muestra la mayor complejidad existente en las relaciones sociales de género: discursos y prácticas que no siempre coinciden, deseos y realidades que se bifurcan, modelos difusos. disrupciones, rupturas, pero también posibilidad de reconstrucciones de las identidades viriles.

\section{Hacia una mejor convivencia en el hogar}

La tensión entre el trabajo y las responsabilidades familiares ha sido una problemática constantemente denunciada desde los albores del feminismo. Sin embargo, la situación de confinamiento ha sacado a la luz con mucha fuerza las desigualdades genéricas en el interior del hogar, en el devenir de las familias que, supuestamente, se construyen en conjunto. La tensión se genera cuando dos personas intentan alejarse afectivamente -tomar distancia-, mientras que la fricción se produce cuando estas pretenden acercarse (Ramírez, 2000). En el caso de los varones, los imperativos sociales hegemónicos han instaurado sobre ellos la posición de autoridad frente al resto de la familia y otras personas, implicando que, cuando éstos asumen ese posicionamiento, tienden a resolver los conflictos desde una asimetría vertical, como jefes del hogar, no solo sobre la prole, sino sobre sus parejas, valiéndose para ello del control y del dominio, e incluso, en muchas ocasiones, a través de la violencia.

La violencia o la amenaza de emplearla por parte de los varones es un medio para asegurar el disfrute continuo de privilegios y de ejercicio de poder, a la vez que un mecanismo compensatorio para restablecer el equilibrio masculino, y afirmarse a sí mismo la supremacía viril. El confinamiento ha incrementado el ejercicio de la violencia masculina en el hogar, dando lugar no sólo a los diversos tipos de violencia que se generan de manera explícita -como son la emocional, verbal, física, sexual y 
económica-, sino también a un ejercicio de violencia simbólica (Bourdieu, 1998), para perpetuar maneras de dominación, pero de un modo más velado y sofisticado, lo que da lugar a formatos invisibles e inapreciables a simple vista, e incluso, naturalizados.

Los femicidios producidos durante este tiempo de confinamiento, 5 en Uruguay y 48 en Argentina, muestran la intensificación de la violencia contra las mujeres, con el peor final posible: el asesinato en manos de varones agresores convivientes. Meler muestra cómo la socialización de género masculina da lugar a una subjetivación viril en la que la angustia y el miedo son convertidos en rabia, "... emoción que tiende a degradar el psiquismo impulsando a los varones hacia la acción, tantas veces destructiva. La convivencia obligada con un varón violento constituye una versión literal de la encerrona trágica, y pone de manifiesto la pertinencia de incluir esta problemática social en las ocupaciones sanitarias" (Meler, 2020:116).

Esto transforma al hogar en un espacio de continuos conflictos, pues los varones no manejan de modo adecuado este interjuego de variables, dando lugar a tensiones producidas ante las obligaciones domésticas, y fricciones frente al hecho de sus acercamientos a la pareja, pues lo juegan desde el lugar de que 'aquí no ha pasado nada'. En relación con la paternidad, se observa que los varones no están asumiendo su rol de padres al ritmo que la situación actual lo requiere, y se vinculan más en actividades de ocio con los hijos, que en las otras requeridas en la vida cotidiana.

Por esta razón, es importante apoyar a los varones en tres aspectos y áreas de desarrollo, en pos de sumar elementos que aporten a una mejor convivencia, más allá del tiempo de confinamiento:

1. Los varones deben aprender la corresponsabilidad doméstica, lo que implica no usar los recursos de la pareja para el propio beneficio, 'pidiendo servicios' a las mujeres (Ramírez, 2000). Esto implicaría que los varones logren generar autosuficiencia logística y emocional, de manera de ocuparse no sólo de la ejecución de las prácticas, sino de su planificación, lo que colaboraría a quitar a las mujeres la "carga mental" de gestión de lo hogareño, históricamente depositada en ellas y que continúa vigente hasta el momento.

2. Es importante dar lugar a las paternidades activas, es decir, a que los varones padres puedan desarrollar la capacidad de estar no sólo presentes en el hogar, sino de estar disponibles, para que sus hijos e hijas puedan contar con ellos en cuestiones emocionales, personales y domésticas. Esto supone ocuparse de los deberes escolares, de la higiene de los más pequeños, y de las prácticas logísticas necesarias para preparar comida y tener el espacio hogareño aseado. La conexión emocional implica ayudar a los hijos e hijas a procesar la nueva realidad de confinamiento, que los conduce a vivenciar diferentes niveles de angustia y ansiedad, por no poder "salir de casa", no poder ver a sus amigos y compañeros de la institución educativa y no poder continuar con algunas actividades que antes le generaban placer.

3. Poder aprehender herramientas que permitan manejar la frustración, generar posibilidades de negociación a partir de la propuesta de reglas conversadas con el resto de la familia, y desarrollar habilidades comunicacionales, en pos de una convivencia saludable con parejas, hijos e hijas. Esto supone convivir con la 
tensión y fricción cotidianas, y tramitarlas sin apelar a la violencia. La autoridad no precisa ser impuesta de manera vertical, sino que, desde la horizontalidad se puede ser un referente adulto que ejerza junto a la pareja -si se tiene-, una lógica democrática, que permita ordenar y organizar la familia, con una ética del cuidado. Los varones deberían intentar realizar un "trabajo interior" para la expresión de su propia ternura, para permitir la demostración de cariño con sus hijos y sus parejas, pues aún están vigentes los parámetros que asocian la masculinidad con la ausencia de demostración afectiva, donde ser fuerte se traslada metonímicamente a una fortaleza emocional que no permite dar cuenta de los sentimientos.

En suma, los varones tendrían que flexibilizar su participación en la convivencia, implicando el desarrollo de habilidades como la creatividad, la apertura y la alteridad, lo que requiere de un esfuerzo para lograr superar los imperativos de la masculinidad hegemónica.

\section{Consideraciones finales}

Estamos inmersos en relaciones de género caracterizadas hoy por las exigencias de los tiempos feministas, a lo que se suma la constante mutación del mundo social como era conocido hasta ahora. En el caso del COVID-19, los protocolos de prevención y aislamiento, con las restricciones que suponen, se enmarcan en lo poco que se conoce del virus, dando lugar a un límite difuso, con una enorme tensión entre la seguridad relativa brindada por las medidas y las amenazas que supone este nuevo estado social de encierro, que a su vez profundiza las reacciones paranoides, la sensación de miedo y de recelo frente al otro, sumado a la ansiedad por el futuro.

Los procesos sociales desencadenados a partir del COVID-19 han dado lugar a transformaciones que afectan tanto las prácticas como las subjetividades. Los nexos tradicionales entre esferas e identidades se han quebrado, para sumirnos en un espacio que puede ser leído como desesperante, o que puede dar lugar a la creatividad, con el fin de sincronizar el espacio hogareño a nuevos usos y a nuevas modalidades vinculares más saludables y colaborativas. En futuras investigaciones, será interesante indagar con mayor profundidad el alcance de estas articulaciones y sus imbricaciones con lo social.

La construcción de la subjetividad masculina está basada en la dominación, la crueldad y la falta de empatía. La subordinación, la complacencia y el agrado son atributos determinantes de 'lo femenino'. Y es acerca de este orden de ambos géneros que hay que reflexionar, para deconstruirlo. En el caso de los varones, se detectaron hasta el momento diversas reacciones frente a la crisis que trajo aparejada la pandemia por el COVID-19, y que pueden clasificarse en:

- Varones ya enmarcados en un proceso de deconstrucción masculina, a los que la situación de confinamiento no les afectó, sino que sirvió para mostrarles que estaban en el camino correcto hacia una mayor conciencia personal y social, posibilitando continuar en el proceso de cambio subjetivo.

- Varones muy angustiados por la situación de confinamiento, debido a una menor posibilidad de insight y a la carencia de herramientas internas que permitan contar con otros parámetros alternativos a los de la masculinidad hegemónica en los 
cuales apuntalar su sentimiento íntimo de masculinidad. Así, están desesperados de que "esto se termine para volver al estado anterior", pues lo consideran un enorme infortunio en el ciclo de sus vidas.

- Varones que están comenzando a utilizar esta crisis para adentrarse en la deconstrucción de su propia masculinidad, potenciando su capacidad empática en sus vínculos afectivos, con hijos, hijas, parejas y otros allegados, y generando corresponsabilidad doméstica y parental. Son aquellos que logran salir del impacto inicial para vivenciar y visualizar esta epidemia como una oportunidad y un desafío para evolucionar, y no como una situación desbordante.

Tal vez el hombre confinado pueda llegar a descubrir, en estos días, que salirse de la lógica productiva, patriarcal y machista genera cambios importantes y positivos en su vida y en la de quienes le rodean; que al incorporar a sus prácticas el cuidado de sí supone también cuidar a otros y cuidar el mundo que habitamos. Cambiar el pequeño mundo de cada uno es la única manera de cambiar de modo global. Y será sólo a través de la toma de conciencia, el propio cuestionamiento, la responsabilidad y la renuncia de los privilegios que este sistema patriarcal otorga a los hombres, por el solo hecho de serlos, como se podrá acabar con este orden androcéntrico. Por eso, pensar en la incomodidad que para el género masculino produce este confinamiento puede ser una oportunidad para que los hombres reflexionen, se impliquen y hagan un proceso de transformación de sus vidas y de las relaciones de género, con el consecuente impacto social. El desafío es no volver a una 'normalidad neoliberal y patriarcal', sino sostener la corresponsabilidad doméstica y las prácticas de cuidado compartidas, para dar lugar a una nueva manera de entender la intersubjetividad.

\section{Bibliografía}

Badinter, Elizabeth (1993): XY, la identidad masculina. Madrid: Alianza editorial.

Bourdieu, Pierre (1998): La dominación masculina. Barcelona: Anagrama.

Connell, Robert (1987): Gender and Power: Society, the Person and Sexual Politics.Cambridge: PolityPress.

Córdoba, María Gabriela (2020): Ser varón en tiempos feministas. Entre el conflicto y el cambio. Buenos Aires: Noveduc.

Delphy, Christyne (1981): "Le patriarcat, le féminisme et leurs intellectuelles". En Nouvelles Questions Féministes \& Questions Féministes [Revista Online] №2, $\quad$ p. 58-74. Disponible en: http://ressourcesfeministes.files.wordpress.com/2000/01/christine-delphyle-patriarcat-le- fc3a9minisme-et-leurs-intellectuelles.pdf

Figueroa, JG. (2020): Varones, género y COVID-19. Colegio de México [Archivo de video del 6 de mayo de 2020] Disponible en https://www.youtube.com/watch?v=IZA4BRQUcF0 
Foucault, Michel (1987): La historia de la sexualidad III: La inquietud de sí. Madrid: Siglo XXI Editores.

Franco, Yago (2020): En Berardi, Franco et al. ¡STOP! COVID-19: ¿Volver a la normalidad? Buenos Aires: El Psicoanalítico.

Fraser, Nancy (2003): “¿De la disciplina hacia la flexibilización? Releyendo a Foucault bajo la sombra de la globalización". Revista Mexicana de Ciencias Políticas y Sociales, Vol 46, No 187, p. 15 -33

Garretón, Manuel (2001): Cambios sociales, actores y acción colectiva en América Latina. (Serie Políticas Sociales №56). Santiago de Chile: CEPAL Naciones Unidas.

Giddens, Anthony (1995): La constitución de la sociedad. Buenos Aires: Amorrortu.

García Canclini, Néstor (1996): “Introducción. Público-privado: la ciudad desdibujada”. En Revista Alteridades, vol. 6, $\mathrm{N}^{\circ}$ 11, p. 5-10. México: Universidad Autónoma Metropolitana Unidad Iztapalapa.

Global Health 5050 (2020). Sex, gender and COVID-19. Recuperado el 17 de mayo, de https://globalhealth5050.org/covid19/

Haraway, Donna (1995): Ciencia, cyborgs y mujeres. Madrid: Ediciones Cátedra.

Keane, John (1995) "Structural Transformations of the Public Sphere". En The Communication Review, vol. 1, núm. 1, p. 1 -22, San Diego.

Lerner, Gerda (1990): La creación del patriarcado. Editorial Crítica: Barcelona.

Meler, Irene (2020): "Pensando en la incertidumbre. Intersubjetividad y género en tiempos de peste". En Berardi, Franco et al. ¡STOP! COVID-19: ¿ Volver a la normalidad? Buenos Aires: El Psicoanalítico.

Ramírez, A. (2000): Violencia Masculina en el Hogar, Editorial Pax México, México D.F, 2007.

Programa de las Naciones Unidas para el Desarrollo (2016). Informe sobre Desarrollo Humano 2016: Desarrollo humano para todos. Nueva York: PNUD.

Quiroga; M. y Pagliarone, M. (2014): "Populismo, estado y movimientos sociales. Posibles articulaciones en los contextos recientes de argentina y Bolivia". Revista Colombia Internacional, N²82, p. 191-219. 